\title{
Research and application of TOPSIS based on AHP in storage mode
}

\author{
Haixia Zeng ${ }^{1, \text { a }}$, Ziqing Zhang ${ }^{1, \mathrm{~b}}$, Yan Chen ${ }^{1, \mathrm{c}}$, and Shan Fan ${ }^{1, \mathrm{~d}^{*}}$ \\ ${ }^{1}$ Mechanical \& Electronic Engineering Division, WenHua College, Wuhan, Hubei, 430074, China
}

\begin{abstract}
In the field of modern logistics, automated warehousing is a very important subject. This paper discusses the layout principles of storage spaces in warehousing, lists different storage methods of goods, and studies how to use the TOPSIS method based on AHP (analytic hierarchy process), summarizes the detailed methods and steps, to find the optimal storage mode, and makes an effective example application of the storage mode of a warehouse management. The research in this paper is suitable for the method choice of similar type of automatic warehouse storage management. The TOPSIS analysis model based on AHP is easy to analyze and calculate, and has universality in the method choice of automatic warehouse storage management.
\end{abstract}

\section{Introduction}

In the automatic warehouse management, the management content can be divided into storage management and delivery management. This paper studies the storage mode and application of automatic warehouse. Between the storage and delivery of goods, the latter mostly requires higher speed, while for the former storage management, we should optimize the layout and storage mode as much as possible to improve the efficiency of delivery.

\section{Layout principle of goods location}

In the warehouse management, it is difficult to standardize the layout of goods location, and it is also difficult to use mathematical formulas and models to express it. However, through detailed investigation and research, according to the characteristics and scale of automated warehousing, a comprehensive optimization principle can be formulated for the layout of goods location, that is, relevant factors that need to be considered, which can be summarized as follows:

(1) The principle of identity or homogeneity. Considering to store the same or similar goods in the same position, the advantage is to facilitate the unified storage, unified deployment and inventory of goods.

(2) Shelf load-bearing principle. Considering the allocation of space according to the weight of the goods, heavy goods should be placed on the bottom and the lighter ones should be places on the top.

(3) Environmental factors. Consider the environmental requirements for the storage of goods, such as space size, temperature, humidity, odor, flammability and explosive,

ae-mail: zenghaixia@foxmail.com, be-mail: 13477046630@139.com,

ce-mail: 15835981@qq.com

*Corresponding author's de-mail: fanshan05@163.com compatibility or repulsion of different goods, etc.

(4) Shipping frequency factor. Consider placing the goods with high delivery frequency close to the shipping port, otherwise, place them far away.

(5) Division principle for similar goods. For some goods with large shipment volume, consider dividing them into multiple areas to prevent congestion when shipping from a single area and improve the delivery efficiency.

For the convenience of later research, the above five points are simply described as the same principle, loadbearing principle, environmental factors, shipping frequency and zoning principle, which are respectively represented by $\mathrm{P} 1, \mathrm{P} 2, \mathrm{P} 3, \mathrm{P} 4$ and $\mathrm{P} 5$.

\section{Storage mode of goods}

The way of goods storage can be divided into fixed goods storage and non-fixed goods storage. Both of them have their own advantages and disadvantages. On this basis, they continue to refine and develop the following storage methods:

(1) Storage mode of fixed goods space. In this way, the storage of goods is strictly fixed in one or more places, and other goods will not be occupied. It is suitable for the occasions where the storage space is large and the cargo space is sufficient. The storage arrangement and shipment are more direct and convenient, but the utilization rate of the storage space is very low, which is easy to cause a large number of empty storage space.

(2) Storage mode of random (not-fixed) goods space. All kinds of goods can be stored in any empty space, without any classification, and the storage location changes at any time. This method can maximize the utilization rate of storage space, and the storage speed is fast, but it will cause the same kind of goods to be stored 
separately, which makes other management more difficult.

(3) Storage mode of classified fixed goods space. Compared with the first method, a classification link is added, goods of the same nature are classified into one group, and the goods of the same group are stored in one or more fixed positions, which other types of goods will not be occupied. In this way, the utilization rate of storage space has been appropriately raised.

(4) Storage mode of classified random (not-fixed) goods space. Compared with the second method, it increases the classification link, which reduces the arbitrariness, and makes moderate balance and coordination in the utilization rate of storage space and the difficulty of management.

(5) Composite storage mode. New storage methods resulting from further integration, such as, on the basis of the storage mode of classified fixed goods space, using the same storage space for two different types of goods; some special areas are set aside for special storage planning. Compared with the above four methods, these methods are more difficult in storage management.

For the convenience of later research, the above five points are represented by $\mathrm{ST}_{1}, \mathrm{ST}_{2}, \mathrm{ST}_{3}, \mathrm{ST}_{4}$ and $\mathrm{ST}_{5}$.

\section{TOPSIS method based on analytic hierarchy process}

TOPSIS is translated into technique for order preference by similarity to an ideal solution, which can be used to sort a finite number of objects according to their proximity to the ideal object, so as to find out the relative advantages and disadvantages of objects. In the selection of the storage mode of automatic warehouse, the optimal storage mode under the current storage environment can be obtained by using this sorting method.

In this paper, based on the five storage methods summarized above, $\mathrm{ST}=\left\{\mathrm{ST}_{1}, \mathrm{ST}_{2}, \mathrm{ST}_{3}, \mathrm{ST}_{4}, \mathrm{ST}_{5}\right\}$, it is necessary to comprehensively consider the principle of multiple goods location layout $\mathrm{P}=\{\mathrm{P} 1, \mathrm{P} 2, \mathrm{P} 3, \mathrm{P} 4, \mathrm{P} 5\}$. The $\mathrm{P}$ set contains elements from different angles, which are called different attribute values in TOPSIS sorting method.

Because the dimensionality and variation interval of each attribute value are different, in order to carry out a unified mathematical analysis, each attribute value in the P set must be de-dimensioned first. AHP is a mathematical tool for quantitative analysis of different attributes. It divides various attributes into interrelated "levels", and describes the "levels" by numerical quantitative method, so as to achieve a unified quantitative description of different attributes. The hierarchical scale comparison table is established as shown in Table 1.

Table 1. The hierarchical scale comparison table

\begin{tabular}{|c|c|}
\hline Hierarchical quantization value & Meaning statement (the relative importance of two attributes) \\
\hline 0 & Both are equally important \\
\hline 1 & The former is more important than the latter by +1 \\
\hline 3 & The former is more important than the latter by +2 \\
\hline 5 & The former is more important than the latter by +3 \\
\hline 9 & The former is more important than the latter by +4 \\
\hline $2,4,6,8$ & In the middle of the above judgment \\
\hline Reciprocal $(1,1 / 2,1 / 3 \ldots)$ & The former is interchangeable with the latter \\
\hline
\end{tabular}

The TOPSIS method is applied to solve the optimal solution of automatic storage management. The specific method includes the following six steps:

(1) Write the decision matrix $A=\left(a_{i j}\right)_{5 \times 5}$. Taking the hierarchical scale comparison Table 1 as the standard, the matrix of storage mode ST and attribute $\mathrm{P}$ is established. For each mode, the interval description mode of the hierarchical quantization value is adopted, and the numeric interval $\mathrm{A}=\left(\mathrm{a}_{\mathrm{ij}}\right)_{5 \times 5}=\left(\left[\mathrm{a}_{\mathrm{ij}}^{\mathrm{L}}, \mathrm{a}_{\mathrm{ij}}^{\mathrm{U}}\right]\right)_{5 \times 5}$ of the expression degree of each attribute is listed.

(2) Write the normalized decision matrix $\mathrm{B}=$ $\left(b_{i j}\right)_{5 \times 5}=\left(\left[b_{i j}^{L}, b_{i j}^{U}\right]\right)_{5 \times 5}$. In order to further avoid the dimensionality and range of variation of each attribute, the following formula group (1) was adopted to normalize the decision matrix A.

$$
b_{i j}^{L}=\frac{a_{i j}^{L}}{\sqrt{\sum_{i=1}^{5}\left(a_{i j}^{U}\right)^{2}}}, \quad b_{i j}^{U}=\frac{a_{i j}^{U}}{\sqrt{\sum_{i=1}^{5}\left(a_{i j}^{L}\right)^{2}}}
$$

(3) Taking the hierarchical scale comparison Table 1 as the standard, the matrix of relative importance among the five attributes is listed, which is called AHP judgment matrix.

After the AHP judgment matrix is obtained, the square root vector of each attribute is solved by the square root method, and then normalized, the proportion weight of each attribute is obtained, that is, the proportion of the importance of each attribute, which is represented by $\mu=$ $\left\{\mu_{1}, \mu_{2}, \mu_{3}, \mu_{4}, \mu_{5}\right\}$.

(4) Write the weighted normalized decision matrix $\mathrm{C}=\left(\mathrm{c}_{\mathrm{ij}}\right)_{5 \times 5}=\left(\left[\mathrm{c}_{\mathrm{ij}}^{\mathrm{L}}, \mathrm{c}_{\mathrm{ij}}^{\mathrm{U}}\right]\right)_{5 \times 5}$ 。

$$
\mathrm{C}=\mu \cdot \mathrm{B}=\left(\left[\mu_{\mathrm{i}} \mathrm{c}_{\mathrm{ij}}^{\mathrm{L}}, \mu_{\mathrm{i}} \mathrm{c}_{\mathrm{ij}}^{\mathrm{U}}\right]\right)_{5 \times 5}
$$

(5) Determine the positive and negative ideal points, and solve the distance from the target to the positive and negative ideal points.

The positive ideal point: $\mathrm{m}_{\mathrm{j}}^{+}=\operatorname{maxc}_{\mathrm{ij}}$; The negative ideal point: $\mathrm{m}_{\mathrm{j}}^{-}=\operatorname{minc}_{\mathrm{ij}}$.

The distance from the target to the positive ideal points: $\mathrm{L}_{\mathrm{i}}^{+}=\sum_{\mathrm{j}=1}^{5}\left|\mathrm{c}_{\mathrm{ij}}^{\mathrm{L}}+\mathrm{c}_{\mathrm{ij}}^{\mathrm{U}}-\mathrm{m}_{\mathrm{j}}^{+\mathrm{L}}-\mathrm{m}_{\mathrm{j}}^{+\mathrm{U}}\right|$.

The distance from the target to the negative ideal points: $L_{i}^{-}=\sum_{j=1}^{5}\left|c_{i j}^{L}+c_{i j}^{U}-m_{j}^{-L}-m_{j}^{-U}\right|$.

(6) Decision method judgment.

Calculate the relative closeness of the target to the 
optimal goal, and the formula is: $\mathrm{ST}_{\mathrm{i}}=\frac{\mathrm{L}_{\mathrm{i}}^{+}}{\mathrm{L}_{\mathrm{i}}^{+}+\mathrm{L}_{\mathrm{i}}^{-}}$.

Find out the minimum value $\operatorname{minST}$ in $\mathrm{ST}=$ $\left\{\mathrm{ST}_{1}, \mathrm{ST}_{2}, \mathrm{ST}_{3}, \mathrm{ST}_{4}, \mathrm{ST}_{5}\right\}$, which is the optimal solution suitable for the automatic warehouse storage management obtained by using TOPSIS method.

\section{Application example}

The following is the application verification of the above method for an automatic warehouse storage management.

(1) Write the numerical interval decision matrix A.

A numerical description of the performance degree to each attribute is determined by questionnaire method. Because of the warehouse management belongs to the work of specialized, therefore, the respondents of the questionnaire survey should be professionals engaged in relevant work and relevant experts, commonly used is the Delphi method, also can take brainstorming mode. Through the investigation, the decision matrix $\mathrm{A}$ is summarized, as shown in table 2 .

Table2. The numerical interval decision matrix A

\begin{tabular}{|c|c|c|c|c|c|}
\hline Storage mode & $\begin{array}{c}\text { Same } \\
\text { principle P1 }\end{array}$ & $\begin{array}{c}\text { Load-bearing } \\
\text { principle P2 }\end{array}$ & $\begin{array}{c}\text { Environmental } \\
\text { factors P3 }\end{array}$ & $\begin{array}{c}\text { Shipping } \\
\text { frequency } \\
\text { P4 }\end{array}$ & $\begin{array}{c}\text { Zoning } \\
\text { principle } \\
\text { P5 }\end{array}$ \\
\hline Fixed $\mathrm{ST}_{1}$ & {$[7,9]$} & {$[6,8]$} & {$[3,5]$} & {$[3,5]$} & {$[5,7]$} \\
\hline Random ST & {$[2,3]$} & {$[5,6]$} & {$[4,6]$} & {$[4,5]$} & {$[2,4]$} \\
\hline Classified fixed ST & {$[6,7]$} & {$[6,7]$} & {$[4,5]$} & {$[4,6]$} & {$[6,8]$} \\
\hline Classified random ST $_{4}$ & {$[5,7]$} & {$[4,5]$} & {$[6,8]$} & {$[5,6]$} & {$[7,9]$} \\
\hline Composite $\mathrm{ST}_{5}$ & {$[4,6]$} & {$[4,6]$} & {$[5,7]$} & {$[5,7]$} & {$[3,5]$} \\
\hline
\end{tabular}

(2) The normalized decision matrix $B$ is shown in table3 (For example: $b_{11}^{\mathrm{L}}=\frac{\mathrm{a}_{11}^{\mathrm{L}}}{\sqrt{\sum_{\mathrm{i}=1}^{\mathrm{L}}\left(\mathrm{a}_{\mathrm{i} 1}^{\mathrm{U}}\right)^{2}}}=\frac{7}{\sqrt{9^{2}+3^{2}+7^{2}+6^{2}+7^{2}}} \approx$ $0.4677)$.

Table3. The normalized decision matrix B

\begin{tabular}{|c|c|c|c|c|c|}
\hline Storage mode & $\begin{array}{c}\text { Same } \\
\text { principle P1 }\end{array}$ & $\begin{array}{l}\text { Load-bearing } \\
\text { principle P2 }\end{array}$ & $\begin{array}{l}\text { Environmental } \\
\text { factors P3 }\end{array}$ & $\begin{array}{c}\text { Shipping } \\
\text { frequency P4 }\end{array}$ & $\begin{array}{c}\text { Zoning } \\
\text { principle P5 }\end{array}$ \\
\hline Fixed $\mathrm{ST}_{1}$ & $\begin{array}{c}0.4677, \\
0.7894]\end{array}$ & $\begin{array}{c}0.4140, \\
0.7044]\end{array}$ & {$[0.2127,0.4951]$} & $\begin{array}{c}0.2294, \\
0.5241]\end{array}$ & $\begin{array}{l}0.3262, \\
0.6312]\end{array}$ \\
\hline Random $\mathrm{ST}_{2}$ & $\begin{array}{c}0.1336, \\
0.2631] \\
\end{array}$ & $\begin{array}{c}0.3450, \\
0.5283] \\
\end{array}$ & {$[0.2836,0.5941]$} & $\begin{array}{c}{[0.3059,} \\
0.5241] \\
\end{array}$ & $\begin{array}{l}0.1305, \\
0.3607] \\
\end{array}$ \\
\hline $\begin{array}{l}\text { Classified } \\
\text { fixed } \mathrm{ST}_{3}\end{array}$ & $\begin{array}{c}0.4009, \\
0.6139]\end{array}$ & $\begin{array}{c}0.4140, \\
0.6163]\end{array}$ & {$[0.2836,0.4951]$} & $\begin{array}{c}0.3059, \\
0.6290]\end{array}$ & $\begin{array}{l}0.3914, \\
0.7213]\end{array}$ \\
\hline $\begin{array}{c}\text { Classified } \\
\text { random } \mathrm{ST}_{4}\end{array}$ & $\begin{array}{c}0.3341, \\
0.6139] \\
\end{array}$ & $\begin{array}{c}{[0.2760,} \\
0.4402]\end{array}$ & {$[0.4253,0.7921]$} & $\begin{array}{c}{[0.3824,} \\
0.6290]\end{array}$ & $\begin{array}{c}0.4566, \\
0.8115]\end{array}$ \\
\hline Composite $\mathrm{ST}_{5}$ & $\begin{array}{c}0.2673, \\
0.5262]\end{array}$ & $\begin{array}{c}0.2760, \\
0.5283]\end{array}$ & {$[0.3544,0.6931]$} & $\begin{array}{c}0.3824, \\
0.7338]\end{array}$ & $\begin{array}{c}0.1957, \\
0.4508]\end{array}$ \\
\hline
\end{tabular}

(3) Write the AHP judgment matrix as shown in table expert investigation.

4. The numerical scale of the matrix is still completed by

Table4. Relative importance AHP judgment matrix

\begin{tabular}{|c|c|c|c|c|c|}
\hline Horizontal/vertical & $\begin{array}{c}\text { Same } \\
\text { principle } \\
\text { P1 }\end{array}$ & $\begin{array}{c}\text { Load-bearing } \\
\text { principle P2 }\end{array}$ & $\begin{array}{c}\text { Environmental } \\
\text { factors P3 }\end{array}$ & $\begin{array}{c}\text { Shipping } \\
\text { frequency } \\
\text { P4 }\end{array}$ & $\begin{array}{c}\text { Zoning } \\
\text { principle } \\
\text { P5 }\end{array}$ \\
\hline P1 & 1 & 3 & 4 & 6 & 7 \\
\hline P2 & $1 / 3$ & 1 & 2 & 3 & 4 \\
\hline P3 & $1 / 4$ & $1 / 2$ & 1 & 2 & 3 \\
\hline P4 & $1 / 6$ & $1 / 3$ & $1 / 2$ & 1 & 2 \\
\hline P5 & $1 / 7$ & $1 / 4$ & $1 / 3$ & $1 / 2$ & 1 \\
\hline
\end{tabular}

Multiply lengthwise and find the square root, such as the first column $\mu_{1}^{\prime}=\sqrt[5]{1 \times \frac{1}{3} \times \frac{1}{4} \times \frac{1}{6} \times \frac{1}{7}}=0.2881$, so we can get $\mu^{\prime}=\{0.2881,0.6598,1.0592,1.7826,2.7865\}$, and then after normalization, $\mu=$
$\{0.0438,0.1003,0.1611,0.2711,0.4237\} \quad$ can $\quad$ be obtained.

(4) Write the weighted normalized decision matrix $\mathrm{C}=\mu \cdot \mathrm{B}$, as shown in table 5 .

Table5. Weighted normalized decision matrix $\mathrm{C}$

\begin{tabular}{|c|c|c|c|c|c|}
\hline Storage mode & $\begin{array}{c}\text { Same } \\
\text { principle P1 }\end{array}$ & $\begin{array}{c}\text { Load-bearing } \\
\text { principle P2 }\end{array}$ & $\begin{array}{c}\text { Environmental } \\
\text { factors P3 }\end{array}$ & $\begin{array}{c}\text { Shipping } \\
\text { frequency P4 }\end{array}$ & $\begin{array}{c}\text { Zoning } \\
\text { principle P5 }\end{array}$ \\
\hline \multirow{2}{*}{ Fixed $\mathrm{ST}_{1}$} & $\begin{array}{c}{[0.0205,} \\
0.0346]\end{array}$ & {$[0.0415,0.0707]$} & {$[0.0343,0.0798]$} & $\begin{array}{c}{[0.0622,} \\
0.1421]\end{array}$ & $\begin{array}{c}{[0.1382,} \\
0.2674]\end{array}$ \\
\hline
\end{tabular}




\begin{tabular}{|c|c|c|c|c|c|}
\hline Random $\mathrm{ST}_{2}$ & $\begin{array}{c}{[0.0059,} \\
0.0115]\end{array}$ & {$[0.0346,0.0530]$} & {$[0.0457,0.0957]$} & $\begin{array}{c}{[0.0829,} \\
0.1421]\end{array}$ & $\begin{array}{c}{[0.0553,} \\
0.1528]\end{array}$ \\
\hline Classified fixed & $\begin{array}{r}{[0.0176,} \\
\mathrm{ST}_{3}\end{array}$ & \multirow{2}{*}[0.0415,0.0618]{} & {$[0.0457,0.0798]$} & $\begin{array}{c}{[0.0829,} \\
0.1705]\end{array}$ & $\begin{array}{c}{[0.1658,} \\
0.3056]\end{array}$ \\
\hline $\begin{array}{c}\text { Classified random } \\
\mathrm{ST}_{4}\end{array}$ & $\begin{array}{r}{[0.0146,} \\
0.0269]\end{array}$ & {$[0.0277,0.0442]$} & {$[0.0685,0.1276]$} & $\begin{array}{c}{[0.1037,} \\
0.1705]\end{array}$ & $\begin{array}{c}{[0.1935,} \\
0.3438]\end{array}$ \\
\hline Composite $\mathrm{ST}_{5}$ & $\begin{array}{c}{[0.0117,} \\
0.0230]\end{array}$ & {$[0.0277,0.0530]$} & {$[0.0571,0.1117]$} & $\begin{array}{c}{[0.1037,} \\
0.1989]\end{array}$ & $\begin{array}{c}{[0.0829,} \\
0.1910\end{array}$ \\
\hline
\end{tabular}

(5) Determine the positive and negative ideal points, negative ideal points. and solve the distance from the target to the positive and

$\mathrm{m}_{\mathrm{j}}^{+}=\{[0.0205,0.0346],[0.0415,0.0707],[0.0685,0.1276],[0.1037,0.1989],[0.1935,0.3438]\} ;$

$\mathrm{m}_{\mathrm{j}}^{-}=\{[0.0059,0.0115],[0.0277,0.0442],[0.0343,0.0798],[0.0622,0.1421],[0.0553,0.1528]\}$.

$\mathrm{L}_{1}^{+}=0.3120, \mathrm{~L}_{2}^{+}=0.5238, \mathrm{~L}_{3}^{+}=0.2052, \mathrm{~L}_{4}^{+}=0.0823, \mathrm{~L}_{5}^{+}=0.3426$.

$\mathrm{L}_{1}^{-}=0.2755, \mathrm{~L}_{2}^{-}=0.0637, \mathrm{~L}_{3}^{-}=0.3823, \mathrm{~L}_{4}^{-}=0.5052, \mathrm{~L}_{5}^{-}=0.2449$.

(6) Decision method judgment.

$\mathrm{ST}_{1}=0.5311, \mathrm{ST}_{2}=0.8916, \mathrm{ST}_{3}=0.3493, \mathrm{ST}_{4}=0.1401, \mathrm{ST}_{5}=0.5831$.

$\mathrm{ST}_{2}>\mathrm{ST}_{5}>\mathrm{ST}_{1}>\mathrm{ST}_{3}>\mathrm{ST}_{4}$, The storage mode closest to the positive ideal point (farthest from the negative ideal point) is ST4. Therefore, the optimal solution suitable for the automatic warehouse storage management in this example is classified random (notfixed) storage.

\section{Conclusions}

This paper studies the application of TOPSIS method based on AHP in the automatic warehouse storage mode, summarizes the detailed methods and steps, and makes an effective example application of the storage mode of a warehouse management, discusses the five kinds of storage ways connecting the five Layout principle of goods location. The research in this paper is suitable for the method choice of similar type of automatic warehouse storage management, for the storage system with bigger difference, and more complex storage and layout principles, this method can still be used to get a suitable conclusion. The TOPSIS analysis model based on AHP is easy to analyze and calculate, and has universality in the method choice of automatic warehouse storage management.

\section{References}

1. ZHANG Y Y, HE G X, WEI H R. (2009) Application of Hybrid TOPSIS Method in Selection of Slotting Optimization Program [J]. Logistics Sci-Tech, No.7: 41-57.

2. Yang K. (2016) Design of an Automatic Warehouse Delivery Picking Subsystem [D]. Huazhong University of Science and Technology: 29-36.

3. ZHANG H W, XIE J W, GE J A, YANG C X, LIU B Z. (2019) Intuitionistic fuzzy set threat assessment based on improved TOPSIS and multiple times fusion [J]. Control and Decision, Vol.34, No.4: 811-815.

4. REN F L, KONG M M. (2019) A fuzzy linguistic TOPSIS decision making method based on alternatives-linguistic terms decision matrixes [J]. Control and Decision, Vol.34, No.3: 602-610.

5. YAN B, LIU S, HUANG Y H. (2017) Application of discrete imperialist competitive algorithm in warehouse order scheduling [J]. Control and Decision, Vol.32, No.1: 39-46.

6. WANG L, DENG J, WANG S Y. (2016) Survey on optimization algorithms for distributed shop scheduling [J]. Control and Decision, Vol.31, No.1: 111. 